\title{
Spider Peripheral Mechanosensory Neurons Are Directly Innervated and Modulated by Octopaminergic Efferents
}

\author{
Alexandre Widmer, Ulli Höger, Shannon Meisner, Andrew S. French, and Päivi H. Torkkeli \\ Department of Physiology and Biophysics, Dalhousie University, Halifax, Nova Scotia, B3H 1X5 Canada
}

Octopamine is a chemical relative of noradrenaline providing analogous neurohumoral control of diverse invertebrate physiological processes. There is also evidence for direct octopaminergic innervation of some insect peripheral tissues. Here, we show that spider peripheral mechanoreceptors are innervated by octopamine-containing efferents. The mechanosensory neurons have octopamine receptors colocalized with synapsin labeling in the efferent fibers. In addition, octopamine enhances the electrical response of the sensory neurons to mechanical stimulation.

Spider peripheral mechanosensilla receive extensive efferent innervation. Many efferent fibers in the legs of Cupiennius salei are GABAergic, providing inhibitory control of sensory neurons, but there is also evidence for other neurotransmitters. We used antibody labeling to show that some efferents contain octopamine and that octopamine receptors are concentrated on the axon hillocks and proximal soma regions of all mechanosensory neurons in the spider leg. Synaptic vesicles in efferent neurons were concentrated in similar areas.

Octopamine, or its precursor tyramine, increased responses of mechanically stimulated filiform (trichobothria) leg hairs. This effect was blocked by the octopamine antagonist phentolamine. The octopamine-induced modulation was mimicked by 8 -Br-cAMP, a cAMP analog, and blocked by Rp-cAMPS, a protein kinase A inhibitor, indicating that spider octopamine receptors activate adenylate cyclase and increase cAMP concentration.

Frequency response analysis showed that octopamine increased the sensitivity of the trichobothria neurons over a broad frequency range. Thus, the major effect of octopamine is to increase its overall sensitivity to wind-borne signals from sources such as flying insect prey or predators.

Key words: octopamine; octopamine receptor; mechanosensory; phentolamine; cAMP; sensory neurons

\section{Introduction}

The biogenic amine octopamine is an invertebrate analog of noradrenaline that modulates a variety of physiological processes (Orchard et al., 1993; Roeder, 1999; Roeder et al., 2003). Octopamine influences the sensitivity of many mechanoreceptors in insects and crustaceans (Pasztor and Bush, 1987; Ramirez and Orchard, 1990; Ramirez et al., 1993; Matheson, 1997; Bräunig and Eder, 1998), but it is not clear whether it acts as a circulating neurohormone or whether it is released locally from efferent endings close to the peripheral targets.

Because a complex network of efferent fibers innervates the most peripherally located parts of spider mechanosensory neurons (Foelix, 1975; Fabian-Fine et al., 1999a, 2000), these neurons provide an important model to investigate octopaminergic mod-

\footnotetext{
Received Nov. 2, 2004; revised Dec. 27, 2004; accepted Dec. 28, 2004.

This work was supported by grants from the Canadian Institutes of Health Research to A.S.F. and P.H.T. and by the Natural Sciences and Engineering Research Council of Canada, the Canadian Foundation of Innovation, and the Nova Scotia Research and Innovation Trust to P.H.T. We thank Dr. Kyung-An Han (Pennsylvania State University, University Park, PA) for the OAMB antibody and Dr. Erich Buchner (University of Würzburg, Würzburg, Germany) for the Synorf 1 antibody.

Correspondence should be addressed to Dr. Päivi H. Torkkeli, Department of Physiology and Biophysics, Dalhousie University, Halifax, Nova Scotia, B3H 1X5 Canada. E-mail: Paivi.Torkkeli@dal.ca. D0I:10.1523/JNEUROSCI.4505-04.2005

Copyright $\odot 2005$ Society for Neuroscience $\quad$ 0270-6474/05/251588-11\$15.00/0
}

ulation. In the tropical wandering spider Cupiennius salei, many of the efferent fibers are GABAergic (Fabian-Fine et al., 1999b), and the mechanosensory neurons are modulated by GABA acting on both ionotropic and metabotropic GABA receptors (Panek et al., 2002, 2003). The large variety of synaptic contacts between the efferent fibers and sensory neurons, between the efferent fibers and glial cells, and between the efferent neurons themselves (Fabian-Fine et al., 2000) suggest that other transmitters also affect these mechanosensilla. Octopamine is a probable candidate, because octopamine-immunoreactive neurons were previously found in the C. salei CNS and free octopamine was detected in its hemolymph (Seyfarth et al., 1993).

In the locust, octopaminergic dorsal unpaired median (DUM) neurons were shown to form terminal networks on sympathetic nerves, and octopamine-immunoreactive varicosities were found on the surfaces of muscle cells innervated by these neurons (Bräunig et al., 1994). In addition, locust hindleg proprioceptors were shown to be directly innervated by DUM neurons and modulated by octopamine (Bräunig and Eder, 1998). These findings suggest that octopamine may act as a local neurotransmitter at peripheral targets rather than (or in addition to) as a circulating neurohormone.

To investigate whether octopamine receptors are present in the spider mechanosensilla, we used a specific antibody against a 


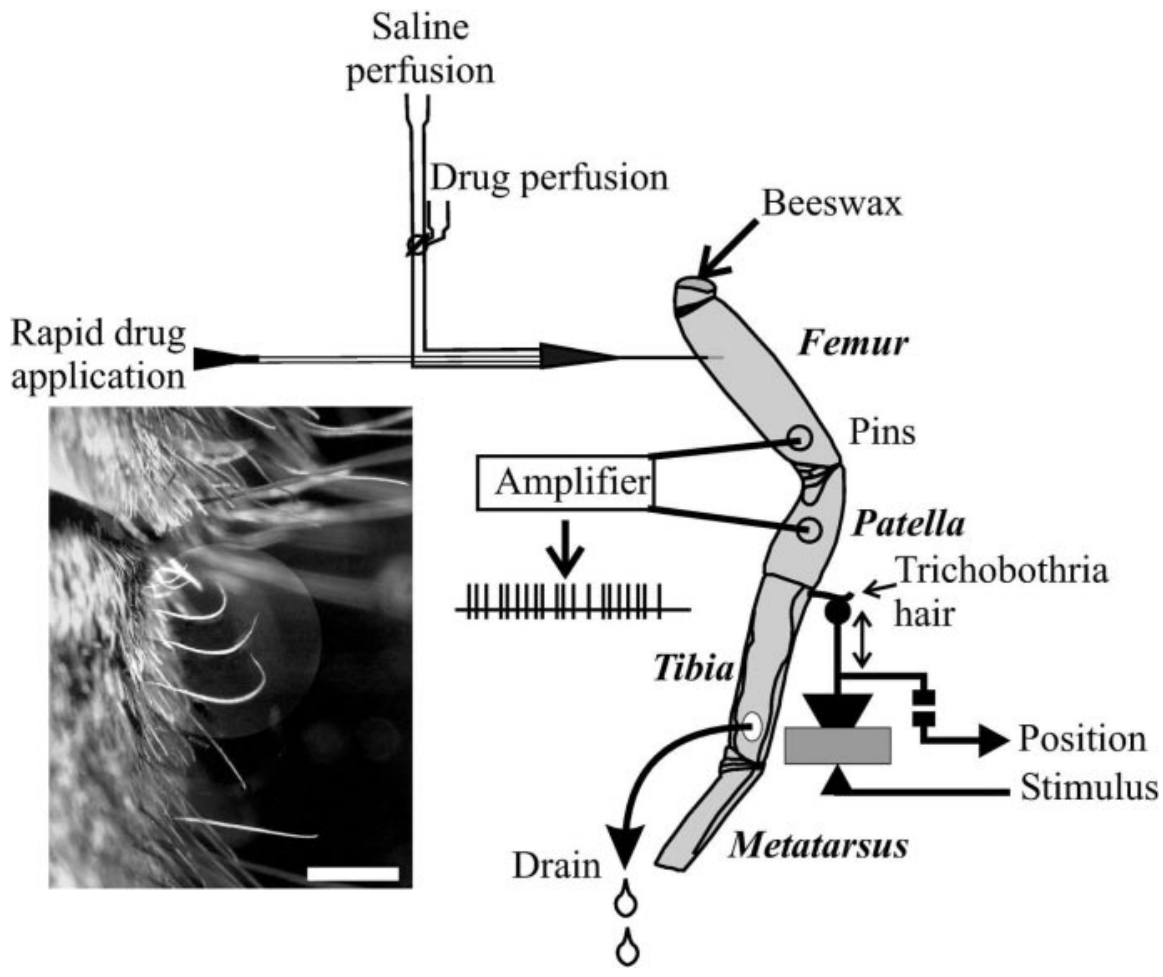

Figure 1. Schematic diagram of the extracellular recording setup. A whole spider leg was perfused with spider saline. A small pump (not shown) was attached to the perfusion system to increase the flow rate through the leg. Chemicals could be applied rapidly via a small tube inside the saline perfusion system or through the drug perfusion system for long-term treatments. Action potentials in neurons innervating the trichobothria sensilla were recorded from the main leg nerve using a pair of silver wires inserted in the femur and patella. Mechanical stimulation of the hair was performed by a tungsten probe attached to a loudspeaker. The inset shows a photograph of three trichobothria hairs on the proximal part of the tibia. Scale bar, $500 \mu \mathrm{m}$.

cloned Drosophila octopamine receptor [anti-OAMB (octopamine receptor in mushroom bodies)] (Han et al., 1998). To determine whether peripherally located octopamine receptors receive direct synaptic inputs, we used double-labeling with the antiOAMB antibody and an antibody against the synaptic vesicle protein synapsin 1 (Klagges et al., 1996; Fabian-Fine et al., 1999a). Immunolabeling with an antibody against octopamine was used to see whether any efferent fibers contain octopamine.

To measure the physiological effects of octopamine on mechanosensory neurons, we recorded responses of filiform hairs (trichobothria) (Barth and Höller, 1999) to mechanical stimuli. Trichobothria were stimulated with pseudorandom noise displacement to test the frequency-dependent effects of octopamine on neuronal sensitivity. We also used pharmacological agents to test the hypothesis that ligand binding to spider octopamine receptors activates adenylate cyclase, leading to an increase in intracellular cAMP concentration and activation of protein kinase A (PKA).

\section{Materials and Methods}

Preparations. Adult Central American wandering spiders (C. salei, Keyserling) of both sexes were taken from a laboratory colony. For most experiments, the legs were autotomized, but for octopamine immunolabeling, spiders were deeply anesthetized with $\mathrm{CO}_{2}$, the tips of their legs were cut off, and the animals were fixed by perfusion through the heart. The legs were then dissected, and the spiders were killed. All experiments followed a protocol approved by the Dalhousie University Committee on Laboratory Animals (03-001I). For immunocytochemical experiments, a piece of cuticle containing anterior femur, patella, and tibia was dissected free from the surrounding tissue. For electrophysiological experiments, whole autotomized legs were used.

Immunocytochemistry. Preparations were fixed in $4 \%$ paraformalde- hyde in PBS for $20 \mathrm{~min}$, followed by several rinses in PBS. Tissue was then permeabilized with $0.5 \%$ Triton X-100 in PBS for $1 \mathrm{~h}$, followed by a $2 \mathrm{~h}$ incubation in blocking solution $(5 \%$ normal goat serum, $3 \%$ skim milk powder, $1 \%$ bovine serum albumin Fraction V, and $0.1 \%$ Triton X-100 in PBS). The primary antibodies were diluted in fresh blocking solution, and the preparations were incubated overnight at $4^{\circ} \mathrm{C}$ in this solution. The primary antibodies used were a polyclonal antibody against Drosophila octopamine receptors, rabbit anti-OAMB (1:1000 dilution; a gift from Dr. K.-A. Han, Pennsylvania State University, University Park, PA) (Han et al., 1998), and a monoclonal antibody against Drosophila synapsin 1, mouse anti-synapsin (SYNORF1, 1:100 dilution; a gift from Dr. E. Buchner, Universität Würzburg, Würzburg, Germany) (Klagges et al., 1996). After antibody incubation, the preparations were washed four times in $0.1 \%$ Triton X-100 in PBS, followed by overnight incubation at $4^{\circ} \mathrm{C}$ in the secondary antibodies in blocking solution. The secondary antibodies used were goat antirabbit CY-3 (111-165-003, 1:600 dilution; Jackson ImmunoResearch, West Grove, PA) for the OAMB antibody and goat anti-mouse Alexa Fluor 488 (A-11029, $10 \mu \mathrm{g} / \mathrm{ml}$; Molecular Probes, Eugene, OR) for the anti-synapsin antibody. Preparations were then washed four times in $0.1 \%$ Triton X-100 in PBS, followed by five rinses in PBS. The hypodermis, carrying the sensilla, was then carefully detached from the cuticle and mounted on a microscope slide in a medium containing Mowiol dissolved in $0.3 \mathrm{M}$ Tris buffer enriched with $2.5 \% \quad 1,4-$ diazabicyclo $(2,2,2$,$) octane to reduce fading.$ For double-labeling experiments, the two primary and two secondary antibodies were used simultaneously.

For octopamine immunolabeling, the whole animal was fixed by perfusion through the heart using 4\% 1-ethyl-3-(3-dimethylaminopropyl) carbodiimide hydrochloride (EDAC) in PBS. The legs were then removed, slit ventrally along the middle of each segment, and fixed an additional $2 \mathrm{~h}$ at $4^{\circ} \mathrm{C}$ in $4 \%$ EDAC. After four washes in PBS, the legs were placed in $0.5 \%$ Triton X-100 in PBS for $30 \mathrm{~min}$, followed by a $1 \mathrm{~h}$ incubation in the blocking solution. Preparations were incubated overnight at $4^{\circ} \mathrm{C}$ in a rabbit anti-octopamine antibody (AB1799; Chemicon, Temecula, CA) in blocking solution at a concentration of 1:500 or 1:1000, then washed four times in $0.1 \%$ Triton X-100 in PBS, followed by incubation in the secondary goat anti-rabbit Alexa Fluor 488 antibody (A11034, $10 \mu \mathrm{g} / \mathrm{ml}$; Molecular Probes) in blocking solution overnight at $4^{\circ} \mathrm{C}$. The preparations were rinsed and mounted in Mowiol as described above. For controls, the primary antibodies were omitted or replaced with normal sera at the same dilutions. There was no labeling in controls.

The preparations were examined under epifluorescence optics with an Axiovert 100 inverted microscope (Carl Zeiss, Oberkochen, Germany) and under a laser-scanning confocal microscope (LSM 510; Carl Zeiss) with an argon-krypton laser for Alexa Fluor 488 (488 nm) and a heliumneon laser for CY-3 (543 nm). Digital images of $0.5-1 \mu \mathrm{m}$ optical sections were captured and analyzed, and the final images were processed using Adobe Photoshop 7 (Adobe Systems, San Jose, CA).

Electrophysiology. All electrophysiological experiments were performed on a gas-driven vibration isolation table (Technical Manufacturing, Peabody, MA) inside a Faraday cage. A whole spider leg was mounted with beeswax onto a Styrofoam support. The dorsal side was placed upward to expose the trichobothria hairs on the proximal part of the tibia (Fig. 1). The tip of the femur was closed with beeswax. A hypodermic needle attached to plastic tubing (outer diameter, $3 \mathrm{~mm}$ ) was 
inserted in the side of the femur and sealed with beeswax. The leg was perfused with spider saline via the tubing and drained from a small hole that was made in the cuticle at the distal part of the tibia. To aid saline flow through the leg, the system was pressurized with a small aquarium pump (Elite 799; Hagen, Montreal, Quebec, Canada). For rapid drug application, smaller tubing (outer diameter, $1 \mathrm{~mm}$ ) was inserted through the $3 \mathrm{~mm}$ tubing all the way to the hypodermic needle. Drugs usually reached the target tissues within 2-3 s. For long-term treatments, pharmacological agents were applied via a manual valve in the saline perfusion tubing.

Two silver wires $(0.25 \mathrm{~mm}$ diameter; World Precision Instruments, Sarasota, FL) were inserted through the femur and fixed with beeswax to serve as extracellular recording electrodes that allowed continuous recording of action potentials from the main leg nerve. The wires were connected to an AC amplifier (P55; Grass Instruments, West Warwick, RI). The signal was amplified 10,000 times and low-pass filtered at $1 \mathrm{kHz}$ by the amplifier.

The hair was stimulated mechanically by a custom-built apparatus consisting of a tungsten wire $(0.25 \mathrm{~mm}$ diameter; A-M Systems, Carlsborg, WA) mounted on a small $(5 \mathrm{~cm}$ diameter) loudspeaker. The long trichobothria hairs were observed through a stereo microscope (SZ60; Olympus, Tokyo, Japan). The stimulator was positioned using a micromanipulator (ALA Scientific Instruments, Westbury, NY), and the tungsten probe was attached to the hair with petroleum jelly. Stimulator position was detected by a matched infrared light-emitting diodephotodiode pair, which also provided second-order servo position control. The stimulus consisted of pseudorandom Gaussian white noise, generated by the computer via a 33-bit binary sequence algorithm, with a maximum amplitude of $\sim 50 \mu \mathrm{m}$.

Action potentials were sampled at a time resolution of $100 \mu$ s and separated from the background noise by a computer algorithm, as described by French et al. (2001). The algorithm identified action potentials as an increase followed by a decrease of voltage through a fixed amplitude threshold within $1.5 \mathrm{~ms}$. To ensure that the algorithm functioned properly, all separations were inspected visually. Action potential signals were digitally filtered by convolution with a $\sin (\mathrm{x}) / \mathrm{x}$ function to band-limit them to the range $0-500 \mathrm{~Hz}$ and produce a regularly sampled signal with a $1 \mathrm{~ms}$ interval. Sampled mechanical displacement was digitally resampled by adjacent point averaging to give a $1 \mathrm{~ms}$ sample interval. The sampled signals were transferred to the frequency domain using the fast Fourier transform (Cooley and Tukey, 1965) in segments of 1024 sample pairs. Frequency response functions (gain and phase) between the input and the output were calculated by direct spectral estimation and plotted as Bode plots of phase and log gain versus log frequency. Coherence functions (Bendat and Piersol, 1980) were calculated from the same data and plotted versus log frequency. Measurements of frequency response functions and coherence functions via direct spectral estimation were described previously (Marmarelis and Marmarelis, 1978; Bendat and Piersol, 1980), and the application of direct spectral estimation to spiking neurons with power-law behavior has been described in detail previously (French et al., 1972). All experiments were controlled by an IBMcompatible computer with custom-written software via 16-bit analogto-digital and 12-bit digital-to-analog converters (National Instruments, Austin, TX).

Chemicals. All chemicals were purchased from Sigma (Oakville, Ontario, Canada), unless indicated otherwise. Drugs were initially dissolved in spider saline, aliquoted, and kept frozen until shortly before the experiments. The following chemicals were used: DL-octopamine hydrochloride (octopamine; O0250), tyramine hydrochloride (tyramine; T2879), phentolamine methanesulfonate salt (phentolamine; P131), 8-bromoadenosine3', 5'-cyclic monophosphate sodium salt (8-Br-cAMP; B7880), and adenosine-3', $5^{\prime}$-cyclic monophosphorothioate (Rp-cAMPS; Rp-isomer, A002-05T; Biolog Life Science Institute, Bremen, Germany).

Statistical analysis was performed by comparing differences between means using a two-sample paired $t$ test with the Prophet 6.0 software (AbTech Corporation, Charlottesville, VA).

\section{Results}

\section{Expression of octopamine receptors in spider peripheral mechanosensilla}

An antibody against an intracellular loop of a Drosophila octopamine receptor (OAMB) (Han et al., 1998) was used to investigate whether these receptors were present in the spider leg mechanosensilla. Examples of anti-OAMB immunoreactivity in VS-3 slit sensilla (Fig. $2 A, D$ ) and neurons innervating tactile hair sensilla (Fig. $2 B, C$ ) are presented. Drawings to indicate the orientation of sensory neurons in each sensillum are shown as insets in each figure. Distinct anti-OAMB-immunoreactive clusters were present in the proximal somata of all mechanosensory neurons (Fig. 2A-D, white arrows), but the extent of labeling varied in other parts of these neurons. In most neurons, the central somata had very little labeling (Fig. $2 B, D$ ). However, some somata had immunoreactive puncta around their perimeter (Fig. $2 A$ ) or in the center (Fig. $2 C$ ). In many neurons, the initial parts of axons also expressed clear anti-OAMB immunoreactivity (Fig. $2 A, C, D$, yellow arrows). On rare occasions, we also detected anti-OAMB labeling in the sensory dendrites (Fig. $2 C$, blue arrow). Using optical $0.5-1 \mu \mathrm{m}$ sectioning by confocal microscopy, we determined that anti-OAMB immunoreactivity was restricted to the sensory neurons and was not present in the efferent fibers or glial cells that surround these neurons.

\section{Location of octopamine receptors in sensory neurons relative to synaptic vesicles in efferent fibers}

To determine whether octopamine receptors in spider peripheral mechanosensory neurons could receive direct synaptic inputs from the surrounding efferent neurons, we performed doublelabeling experiments with the anti-OAMB antibody and an antibody against Drosophila synapsin 1 (Klagges et al., 1996). Previous electron microscopical investigation showed that the synapsin antibody labeled specifically synaptic vesicles in the efferent neurons surrounding the spider mechanosensory neurons (Fabian-Fine et al., 1999a, 2000). An example of anti-OAMB/ anti-synapsin double-labeling in a VS-3 slit sensillum is shown in Figure $2 D-F$. All six neurons in this image had anti-OAMBlabeled clusters in the proximal somata (Fig. $2 D$, white and green arrows) and in the initial axon segments (Fig. $2 D$, yellow and blue arrows). Anti-synapsin-immunoreactive clusters in the fine efferent fibers were concentrated on the axonal area (Fig. $2 E$, yellow and blue arrows), but they were also present around the somata, including the proximal region (Fig. $2 E$, white arrow). The superimposed image (Fig. $2 F$ ) shows that many of the antiOAMB-labeled clusters were in close proximity with the antisynapsin-labeled clusters (Fig. $2 F$, white, yellow and blue arrows). However, some areas with strong anti-OAMB labeling had only a very small amount of anti-synapsin labeling in the vicinity (Fig. $2 F$, green arrow). Lack of anti-synapsin immunoreactivity in these locations may be caused by some of the efferent fibers being separated from sensory neurons when the hypodermis membrane was detached from the cuticle. The close location of anti-synapsin and anti-OAMB labeling is also seen in the single orthogonal sections from the $X$ and $Y$ planes of one proximal somatic region (Fig. $2 F$, insets). One $Z$ plane $1 \mu \mathrm{m}$ section from another similar location is also shown.

The location of anti-synapsin-labeled clusters in close vicinity with most of the anti-OAMB-labeled clusters suggests that there may be direct synaptic input to octopamine receptors by periph- 

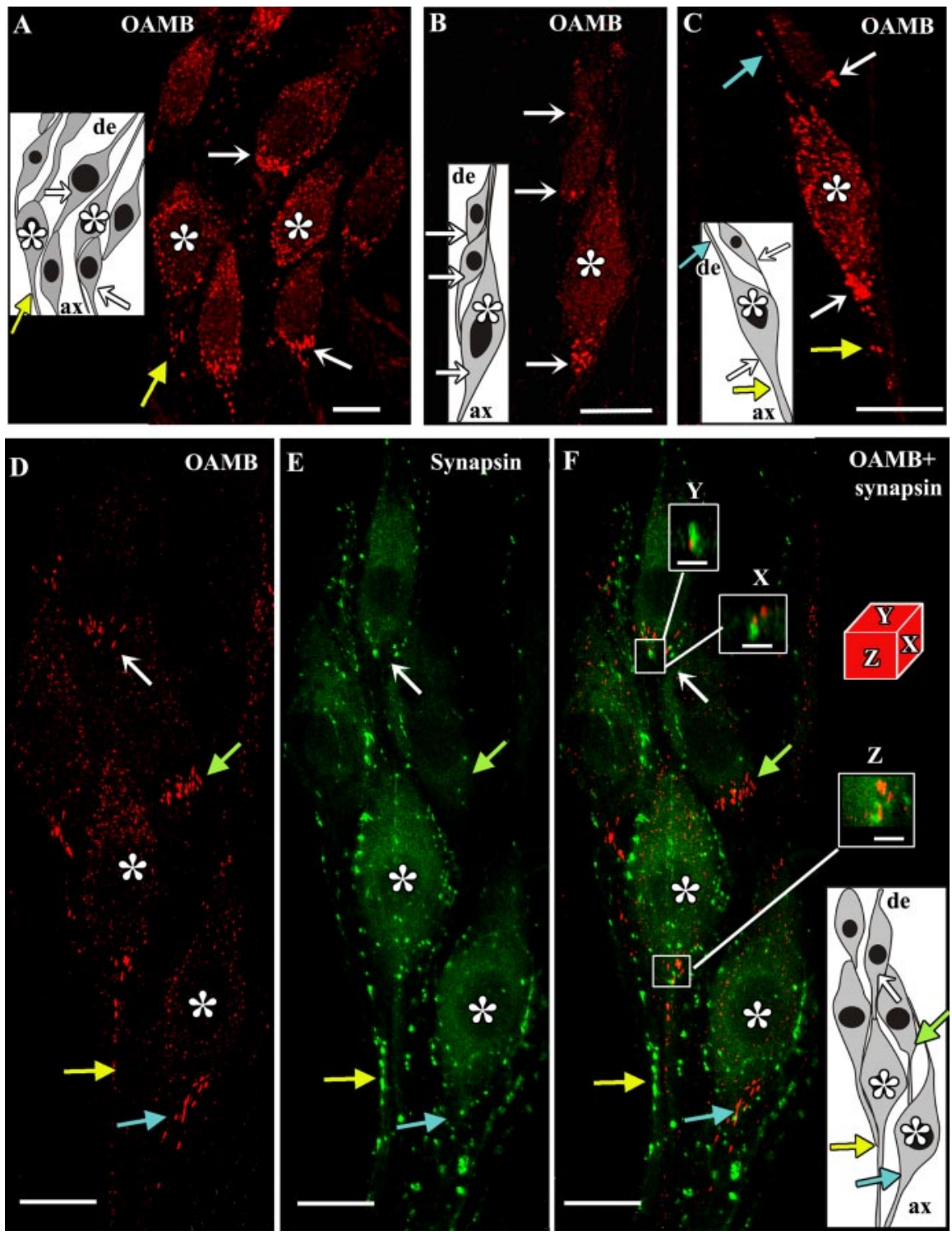

Figure 2. Two-dimensional confocal projections of anti-OAMB- and anti-synapsin-immunolabeled mechanosensilla in spider leg. Anti-OAMB labeling $(A-D)$ is indicated in red (CY-3), and anti-synapsin labeling $(E)$ is indicated in green (Alexa Fluor 488). $F$ is a superimposed image of $D$ and $E$. Schematic diagrams in each image show the arrangements of mechanosensory neurons and locations of the arrows in the fluorescent images. A, Anti-OAMB labeling in sensory neurons innervating a VS-3 organ. Anti-OAMB labeling was present in the cell bodies ( 2 marked with asterisks) but especially strongly concentrated in their most proximal parts (white arrows). Immunoreactive clusters were also present in the initial axon segments (yellow arrow). $B$, Anti-0AMB labeling in three neurons innervating a tactile hair. Only the most proximal parts of these neurons had anti-0AMB-immunoreactive clusters (white arrows). There was no labeling in other parts of these cell bodies (largest marked with an asterisk). C, Two neurons innervating a tactile hair. Both neurons had anti-OAMB immunoreactivity in the proximal somata (white arrows), but the larger neuron had clear labeling also in the whole soma (asterisk), in the dendrite (blue arrow), and in the axon (yellow arrow). D-Fshow double-labeling of a VS-3 organ with anti-OAMB and anti-synapsin antibodies. Very little anti-OAMB immunoreactivity was present in the cell bodies ( 2 marked with asterisks), but their proximal parts (white and green arrows in $D$ ) and some of the axons (yellow and blue arrows in D) were clearly labeled. Anti-synapsin-immunoreactive fine fibers were most clearly visible around axons of the sensory neurons (yellow arrow in $E$ ), but immunoreactive puncta were also present in fibers surrounding the cell bodies (asterisks). Some of the anti-synapsin-labeled clusters were adjacent to anti-0AMB-labeled clusters (white, yellow, and blue arrows in F). However, some areas with dense anti-OAMB-labeled clusters had only a few anti-synapsin-labeled puncta present (green arrows in $D-F$ ). The insets in $F$ show single orthogonal $1 \mu \mathrm{m}$ sections from planes $X, Y$, and $Z$ at the areas indicated. Scale bars: $A-F, 20 \mu \mathrm{m} ; F$ (inset), $5 \mu \mathrm{m}$.

eral efferents. However, peripheral synapses that use other transmitters have previously been identified in the spider mechanosensilla (Fabian-Fine et al., 1999b, 2000), making it possible that these colocations are only accidental.

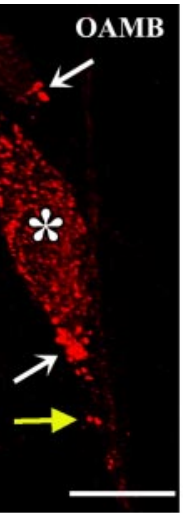

Octopamine in the peripheral efferent fibers

For the presynaptic sites to be able to release octopamine, some of the efferent fibers would need to contain octopamine. To test this hypothesis, we performed immunocytochemical experiments using an antibody against octopamine on wholemount preparations of spider patellar hypodermis. Figure 3 shows examples of anti-octopamine labeling in the efferent fibers innervating the sensory neurons. Drawings indicating orientation of sensory neurons, or the leg nerve, are shown as insets in each image. These drawings also indicate locations of the immunoreactive fibers. Figure $3 A$ shows two neurons of a VS- 3 sensillum (somata are indicated by asterisks). Fine anti-octopamine-immunoreactive fibers were clearly visible above the axons and proximal parts of the cell bodies, but labeling was more difficult to distinguish at the cell bodies. One anti-octopamine-immunoreactive branch was seen extending in a different direction, probably innervating other sensory neurons in the leg. Examples of antioctopamine labeling in the main leg nerve (Fig. $3 B$ ) and on top of the axons of two groups of neurons that innervate tactile hairs (Fig. 3C,D) are presented.

Anti-octopamine labeling was not continuous, but intermittent labeling was detected in the main leg nerve (Fig. $3 B$, arrows) and on top of the axons close to the sensory neurons (Fig. $3 A, C, D$ ). Some immunoreactivity was visible on the somatic area, but it was not possible to follow branches around the somata. Diameters of anti-octopamine-immunoreactive fibers were $\sim 1 \mu \mathrm{m}$. Only one fine efferent fiber was found innervating each mechanosensillum, and in some cases, it was possible to see it branching to each sensory neuron (Fig. 3A). These results suggest that each of the mechanosensory neurons in the spider leg is directly innervated by one octopamine-containing efferent.

\section{Octopamine increased the firing frequency of spider mechanosensory neurons}

To test the effect of octopamine on neuronal excitability, we developed a method that allowed long-lasting recordings during mechanical stimulation (see Materials and Methods). A whole spider leg was perfused with saline, and the action potentials propagating along the main leg nerve were recorded via wires inserted into the femur and patella (Fig. 1). Filiform air movement receptors, the trichobothria hairs (Barth and Höller, 1999), on the proximal part of the tibia were stimulated with mechanical pseudorandom white noise displacement. These hairs are innervated by three or four 

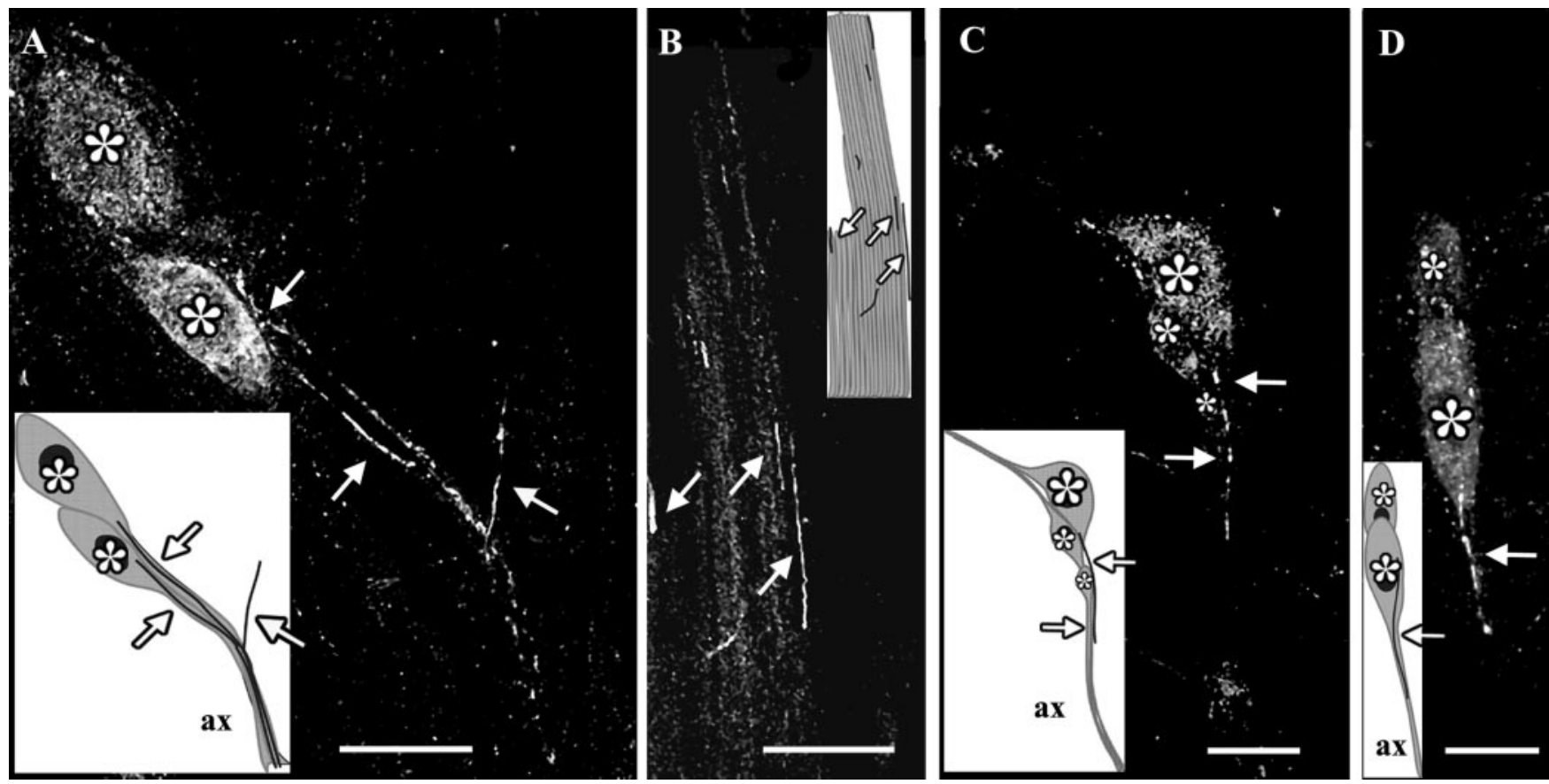

Figure 3. Two-dimensional confocal projections of anti-octopamine-labeled efferent fibers innervating spider mechanosensory neurons. Schematic diagrams in each image show the arrangements of the mechanosensory neurons, the anti-octopamine-labeled fibers, and the locations of arrows in the fluorescent images. A, Two anti-octopamine-immunoreactive branches (arrows) extend to the cell bodies of two neurons of a VS-3 organ. Another anti-octopamine-immunoreactive branch (arrow) is also visible in this image. $B$, The main leg nerve leading to the VS-3 organ had intermittent anti-octopamine labeling (arrows). C, A single anti-octopamine-immunoreactive fiber (arrows) passed over the axons of the three neurons innervating a tactile hair. D, A single anti-octopamine-immunoreactive fiber passed over the axons and cell bodies of two neurons of a tactile hair sensilla. Scale bars, $20 \mu \mathrm{m}$.

sensory neurons (Fabian-Fine et al., 2002). These neurons do not display tonic activity without mechanical stimulation. Action potentials with the highest amplitudes, presumably from one of these neurons, were selected for analysis. Figure $4 \mathrm{~A}$ shows an example of part of one such recording.

To obtain clear discrimination of action potential firing frequencies under different conditions, the original recording was converted into impulses per second using 1-s-wide bins. Figure $4 B$ shows typical examples of 6 min duration recordings performed when the leg was perfused by normal spider saline (control) and when $1 \mathrm{~mm}$ octopamine was added to the perfusion. In both cases, the firing frequency decreased sharply during the first $60 \mathrm{~s}$ of recording. Under control conditions, the firing reached a plateau level where it remained during the remaining $\sim 5 \mathrm{~min}$ of the recording. When octopamine was applied, the firing frequency increased sharply, close to the level before adaptation. In six experiments with the octopamine precursor tyramine, the firing frequency of the trichobothria neurons increased similarly as with octopamine (Fig. 4C).

Dose-response relationship of octopamine-induced response The amplitude and duration of octopamine-induced increase in firing frequency was dependent on octopamine concentration. With $1 \mathrm{~mm}$ octopamine, the effect was still seen $5 \mathrm{~min}$ after application (Fig. 4B). With lower concentrations, the effect was smaller and of shorter duration. To quantify the effect of octopamine concentration on firing frequency, a series of experiments were performed with octopamine concentrations of 100 $\mathrm{nm}$ to $1 \mathrm{~mm}$. The final concentration at the site of action was uncertain but probably lower because of dilution with saline in the perfusion system and in the leg. To obtain an accurate estimate of the increase in firing frequency, the base firing frequency was subtracted from the recordings (Fig. 5A). First, an exponen- tial decay function was fitted to the first $30-60 \mathrm{~s}$ before octopamine application in each recording using a minimum error procedure, with accuracy verified by eye in each experiment. The fitted line was used as a base level of firing in each neuron and subtracted from the original trace. The resulting trace was used to estimate the peak response to octopamine by averaging its 20 highest points. Peak responses from 36 cells were used to plot a dose-response curve (Fig. 5B).

The Hill coefficient of the octopamine response was 0.96, indicating that octopamine receptors are non-cooperative and that a single agonist molecule binding is sufficient to activate the receptor. Similar findings have previously been made for molluscan octopamine receptors (Gerhardt et al., 1997a). The octopamine concentration at half-maximal response $\left(\mathrm{EC}_{50}\right)$ was $1.39 \mu \mathrm{M}$, which is comparable with previous studies in insects and molluscs (Ramirez and Orchard, 1990; Gerhardt et al., 1997a; Han et al., 1998; Van Poyer et al., 2001).

The peak responses of six recordings in which tyramine was used as an agonist were also plotted on the dose-response plot (Fig. $5 B$, triangles). These responses were in the lower range of responses to octopamine, suggesting that tyramine is slightly less potent than octopamine in increasing the firing frequency of trichobothria neurons. Previous studies have also indicated that tyramine is a less potent agonist of octopamine receptors (Evans, 1981; Ramirez and Orchard, 1990; Gerhardt et al., 1997a; Han et al., 1998; Van Poyer et al., 2001; Grohman et al., 2003; Bischof and Enan, 2004).

\section{Octopamine increases the overall sensitivity of spider mechanosensory neurons}

Octopamine clearly increased the firing frequency of the spider trichobothria neuron when a pseudorandom white noise mechanical stimulus was applied. To learn whether this effect varied 

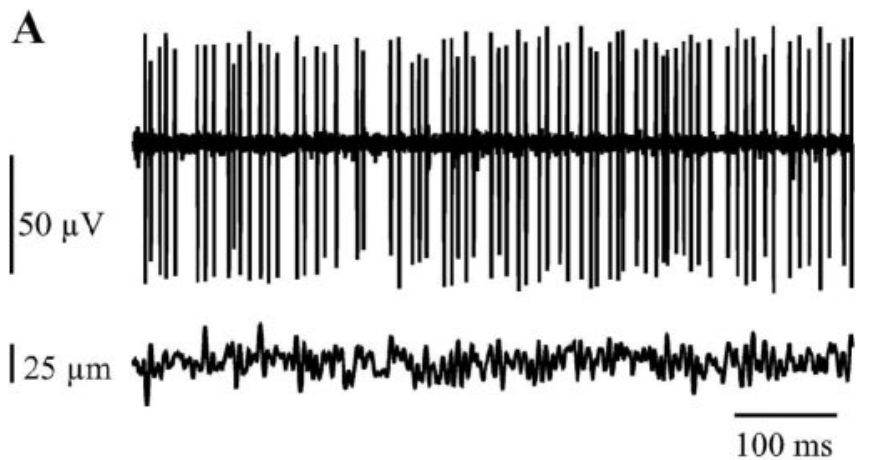

B

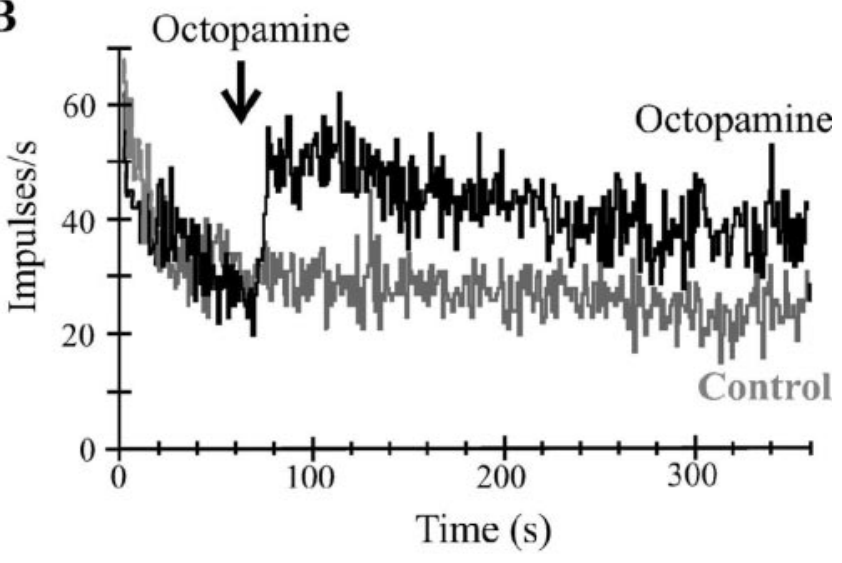

C

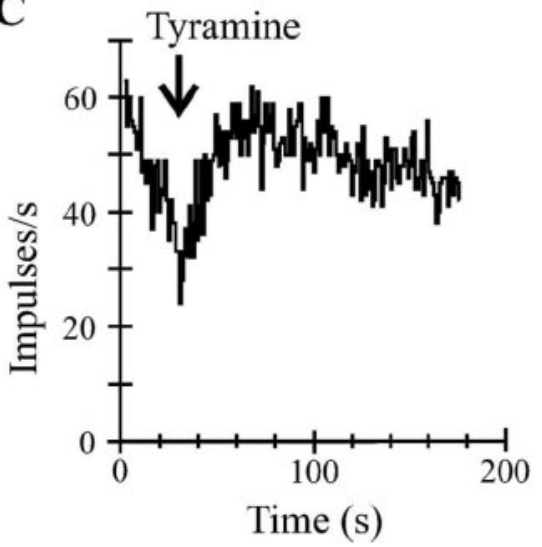

Figure 4. Extracellular recordings from the neurons innervating trichobothria sensilla in the spider tibia. $A$, A portion of an original recording showing a train of action potentials (above) elicited with mechanical white noise stimulation (below). $B$, The action potential frequency was calculated using 1-s-wide bins. The gray trace shows the firing frequency of a neuron that was perfused with normal spider saline (control). Adaptation caused a clear decrease in firing frequency during the initial $\sim 60 \mathrm{~s}$ of recording. The black trace shows the firing frequency of the same neuron when $1 \mathrm{~mm}$ octopamine was applied to the perfusion after initial adaptation (octopamine). The time of octopamine application is indicated by an arrow. The firing frequency increased immediately close to the initial level before adaptation and remained at an increased level during the remaining recording period. C, Application of $10 \mu \mathrm{m}$ tyramine produced a similar increase in the firing frequency as octopamine.

with stimulus frequency and whether it also affected the information capacities of these neurons, we performed frequency response analysis from nine experiments in which $1 \mu \mathrm{M}$ to $1 \mathrm{mM}$ octopamine was applied. Each data set was analyzed using a minimum of $50 \mathrm{~s}$ of data immediately after the firing frequency increased in response to octopamine application. For each cell, initial control recordings were performed in normal spider saline, and frequency response analysis was performed on the same
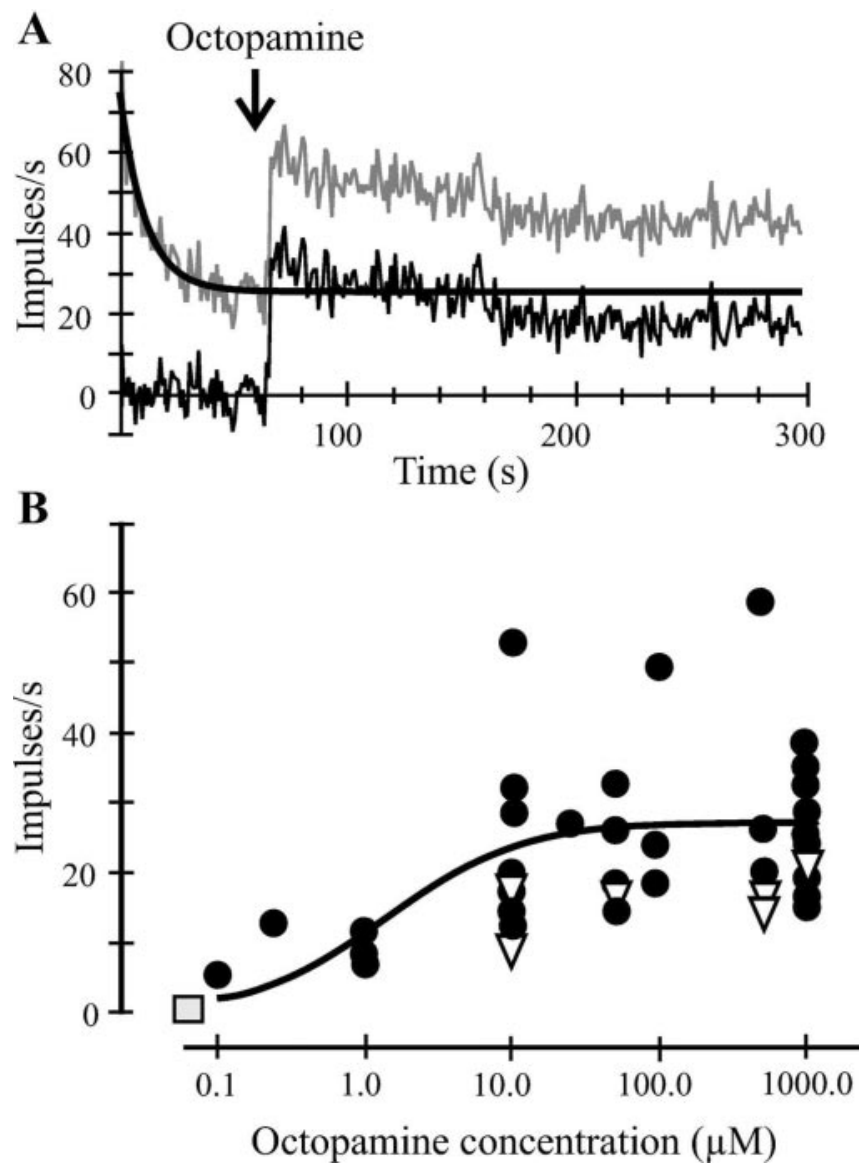

Figure 5. Dose-response relationship of octopamine response. $A$, The gray trace shows the original firing frequency of a trichobothria neuron before and after octopamine application. An exponential decay function was fitted to the adaptation period before octopamine application (thick solid line), and this trace was subtracted from the original gray trace. The peak response was calculated by averaging the 20 highest points of the resulting black trace. $B$, Peak responses were plotted against agonist concentration and fitted with a logistic Hill equation $(Y=$ $Y_{\text {max }}[C]^{n} /\left([C]^{n}+\left[\mathrm{EC}_{50}\right]^{\mathrm{n}}\right)$, where $Y$ is the response, $Y_{\max }$ is the maximal response, $[C]$ is the octopamine concentration, $\left[\mathrm{EC}_{50}\right.$ ] is the half-maximal effective concentration, and $n$ is the Hill coefficient. The $\left[\mathrm{EC}_{50}\right.$ ] value was $1.39 \mu \mathrm{m}$, and the Hill coefficient was 0.96 . The gray square represents the peak value (mean \pm SD) from five control recordings in which the agonist was not applied. Note that the SD is smaller than the gray square. Peak responses to tyramine are shown as triangles.

time window as for the experiments with octopamine. Figure 6 shows typical examples of estimated gain, phase, and coherence functions for one neuron under control conditions and after octopamine application.

All frequency response functions could be fitted with a linear relationship between log gain versus log frequency corresponding to a power law, or fractional differentiation model (Eq. 1):

$$
G(f)=A f^{k}
$$

where $f$ is the frequency, $A$ is a constant, and $k$ is the fractional exponent. This form of frequency response is well known in sensory receptors (Thorson and Biederman-Thorson, 1974; French, 1984) and has been described in two different slit sense organs of this spider (Bohnenberger, 1981; French et al., 2001). Parameter A describes the overall sensitivity of the neuron, and parameter $k$ describes the adaptation properties of the neuron with $k=0$ indicating that the response is not dependent on frequency. The power law model predicts a constant phase lead of $\mathrm{k} \times 90^{\circ}$, independent of frequency, but conduction of action potentials from 

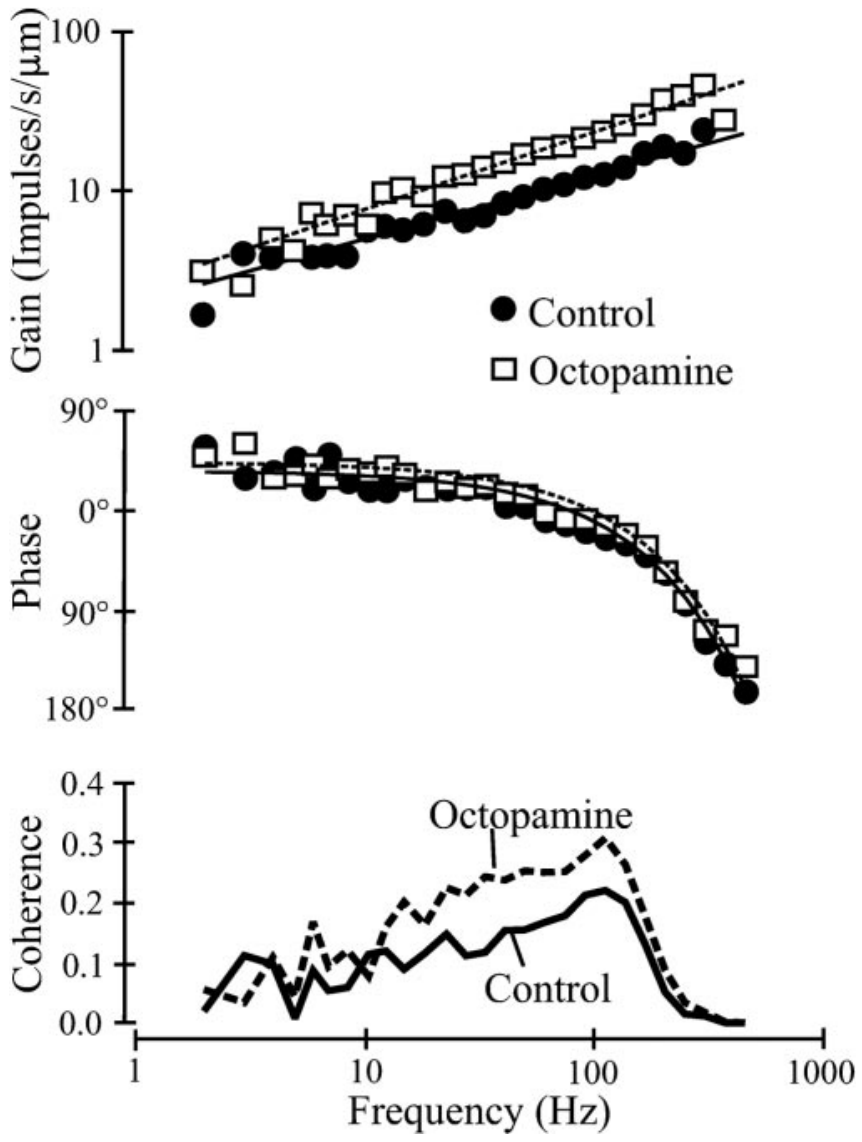

Figure 6. Octopamine effects on frequency response and coherence functions of a spider trichobothria neuron. Fitted lines show Equations 1 and 2 fitted to the gain and phase data with $k=0.40$ and $0.48, A=2.0$ and $2.5 \mathrm{impulses} / \mathrm{s} / \mu \mathrm{m}$, and $\Delta t=1.29$ and $1.25 \mathrm{~ms}$ for control and octopamine recordings, respectively. Maximum coherence values were 0.22 and 0.31 , and information capacities from Equation 3 were 53.0 and 80.8 bits/s for control (solid line) and octopamine (dotted line) recordings, respectively.

Table 1. Statistical analysis of three parameters obtained from frequency response analysis (Eqs. 1-3) before (control) and after (octopamine) octopamine application

\begin{tabular}{lccl}
\hline Parameter & Control & Octopamine & Significance $(p)$ \\
\hline$A$ (impulses $/ \mathrm{s} / \mu \mathrm{m})$ & $1.75 \pm 1.33$ & $2.11 \pm 1.26$ & 0.0149 \\
$k$ & $0.37 \pm 0.13$ & $0.40 \pm 0.16$ & 0.3687 \\
$R$ (bits $/ \mathrm{s})$ & $47.4 \pm 16.7$ & $58.4 \pm 20.4$ & 0.0255 \\
$n$ & 9 & 9 &
\end{tabular}

Values are given as means $\pm \mathrm{SD}$. $A$, Sensitivity; $k$, fractional exponent; $R$, information capacity; $n$, number of experiments.

the stimulated neuron to the recording wires caused a time delay, $\Delta t$, adding a frequency-dependent phase lag of $\Delta t \times f \times 360^{\circ}$. Combining these two factors, the phase relationship was fitted by Equation 2:

$$
P(f)=k \times 90^{\circ}-\Delta t \times f \times 360^{\circ},
$$

where $P(f)$ is the phase lag as a function of frequency.

All experiments were fitted with Equations 1 and 2, giving fitted parameters of $A, k$, and $\Delta t$. Mean values of $A$ and $k$ for the control and octopamine experiments are given in Table 1. Results under different conditions were compared by a paired $t$ test. The value of $A$ increased significantly after octopamine application, but there was no statistically significant difference in $k$ under the two different conditions. These results indicate that the overall sensitivity of the neurons increased in response to octopamine, but there was no change in adaptation properties; the increase in sensitivity was identical at all frequencies. This can also be seen in the gain and phase plots in Figure 6, in which the gain increased similarly at all recorded frequencies and the phase relationship was unchanged.

Coherence functions, $\gamma^{2}(f)$, were calculated from the same data to obtain the linear correlation between the input and output signals (Bendat and Piersol, 1980). The coherence function is unity for a linear noise-free system but reduced by the presence of nonlinearity or uncorrelated noise in the system. Examples under control conditions and after octopamine application are plotted together with the frequency response functions in Figure 6. Coherence functions were used to estimate information capacities under control conditions and after octopamine application. The linear information capacity $R$ was estimated by combining the relationship between coherence and the signal/noise ratio with the Shannon formula (Shannon and Weaver, 1949; French et al., 2001) to give Equation 3:

$$
R=\int \log _{2}\left\{1 / 1-\gamma^{2}(f)\right\} d f .
$$

Information capacity, measured in bits per second, is the maximum achievable rate of information transmission through a communication system. Mean values of information capacities under control conditions and after octopamine application are given in Table 1 . There was a statistically significant increase in information capacity after octopamine application, indicating that octopamine increased the ability of the neurons to transmit sensory information. Similar effects of firing rate on information capacity have been reported before in VS-3 neurons (French et al., 2001).

\section{Phentolamine effects on the firing rate and octopamine-induced response}

Phentolamine is the most widely used antagonist of octopamine receptors (Evans, 1981; Ramirez and Orchard, 1990; Howell and Evans, 1998; Degen et al., 2000). It is an effective, but not specific, blocker of these receptors and has also been shown to directly inhibit neuronal excitability at high concentrations (Ramirez and Pearson, 1990). This local anesthetic effect is believed to occur through interaction with voltage-activated $\mathrm{Na}^{+}$channels (Ramirez and Pearson, 1990; Ramirez and French, 1990). Here, we confirmed that phentolamine had both of these effects on spider trichobothria neurons.

Figure 7 shows an experiment in which $100 \mu \mathrm{M}$ phentolamine was applied to the perfusion solution while the trichobothrium was stimulated mechanically. The firing rate initially decreased below the normal plateau level but returned to the normal level after $\sim 10 \mathrm{~min}$, although phentolamine was maintained in the perfusion. When $50 \mu \mathrm{m}$ octopamine was now applied, the typical stimulatory effect did not occur. Phentolamine was then removed, and the leg was perfused with spider saline until the typical octopamine response returned (Fig. 7). Similar inhibitory effects of phentolamine on firing frequency were recorded in 7 of 14 experiments in which $10-100 \mu \mathrm{M}$ phentolamine was applied. In the remaining seven experiments, phentolamine had no clear effect on its own. These were significantly lower concentrations than described previously for the anesthetic effect of phentolamine on locust and cockroach mechanoreceptors, in which $200-500 \mu \mathrm{M}$ phentolamine was needed to inhibit the neurons (Ramirez and Pearson, 1990). The octopamine effect was reversibly blocked by phentolamine in five of nine experiments. 


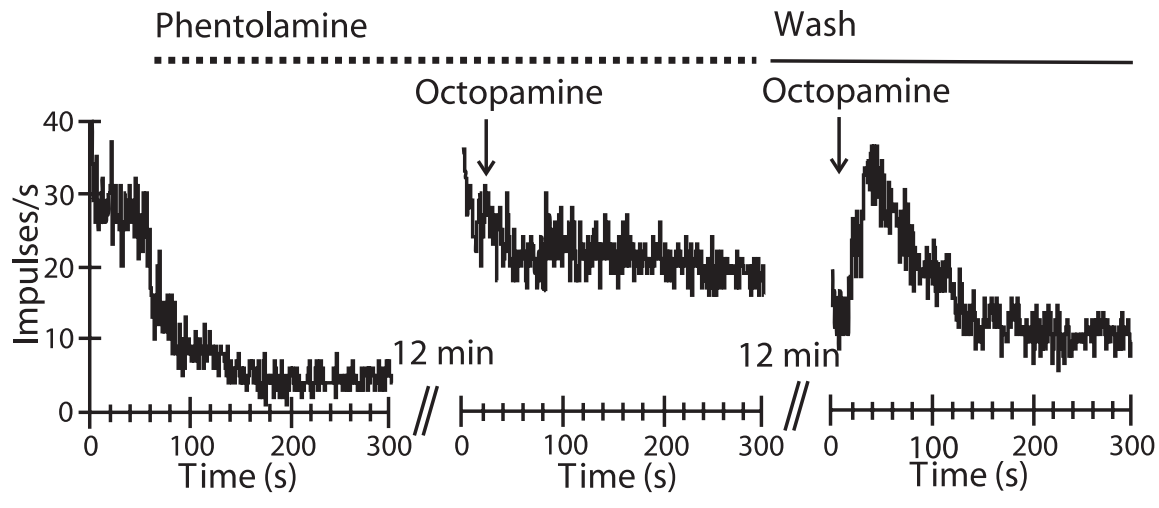

Figure 7. Phentolamine effects on firing frequency and octopamine response. When $100 \mu \mathrm{m}$ phentolamine was added to the perfusion solution (dotted line), the firing frequency of mechanically stimulated trichobothria neuron decreased (left). After 12 min, the firing frequency returned to the control level. When $50 \mu \mathrm{m}$ octopamine was applied with phentolamine, the firing frequency did not increase (middle). Phentolamine was then removed from the perfusion solution and replaced with normal spider saline (wash), and the neuron was washed for an additional 12 min period. When $50 \mu$ octopamine was applied, the neuron responded with an increase in firing frequency (right).
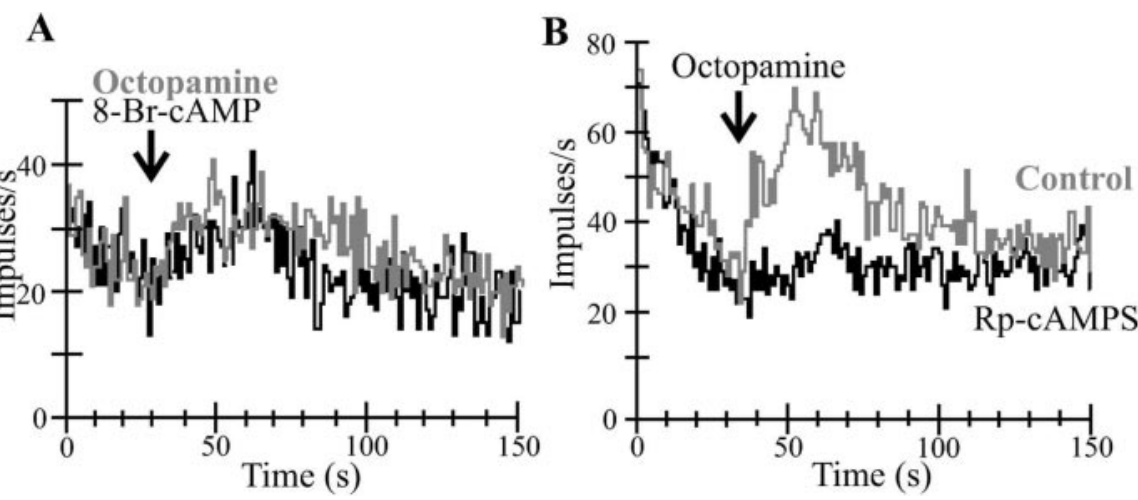

Figure 8. Octopamine-induced second-messenger pathway in the spider trichobothria neuron. A, Application of $1 \mathrm{~mm} 8-\mathrm{Br}$ CAMP increased the firing frequency of a mechanically stimulated neuron (black trace). The time course and amplitude of this response were similar to that observed when $50 \mu \mathrm{m}$ octopamine was applied to the same preparation (gray trace). $B$, When perfused in normal spider saline, this neuron responded to application of $10 \mu \mathrm{m}$ octopamine with an increase in firing frequency (gray trace). After the perfusion solution was supplemented with an inhibitor of PKA (100 $\mu \mathrm{m}$ Rp-cAMPS), the response to $10 \mu \mathrm{m}$ octopamine was nearly abolished (black trace).

In four experiments, the normal octopamine effect did not return after wash.

\section{Second-messenger pathway of the spider octopamine receptor}

All known octopamine receptors are coupled with G-proteins, but they show different couplings with second-messenger systems. These include activation and inhibition of adenylate cyclase, leading to an increase or decrease in cAMP, and activation of an inositol phosphate pathway, leading to increase in intracellular $\mathrm{Ca}^{2+}$ (for review, see Roeder, 1999). Some receptors also activate $\mathrm{Cl}^{-}$channels (Gerhardt et al., 1997b). Here, we investigated the most common of these pathways, activation of adenylate cyclase leading to increased cAMP concentration. We first tested whether an analog of cAMP, 8-Br-cAMP, could mimic the response of the cell to octopamine. Figure $8 \mathrm{~A}$ shows an example of a recording in which $50 \mu \mathrm{M}$ octopamine or $1 \mathrm{~mm} 8$-Br-cAMP was applied to the perfusion system while the trichobothrium was stimulated mechanically. 8-Br-cAMP induced an increase in the firing frequency, similar in amplitude and time course to octopamine in all four recordings in which it was tested.

The next step in the second-messenger pathway after cAMP synthesis is activation of PKA. We tested whether a phosphodiesterase-resistant competitive inhibitor of PKA types I and II, RpcAMPS, would inhibit the response of the neuron to octopamine. Figure $8 B$ shows an example of a recording in which the leg was perfused initially in normal spider saline and $10 \mu \mathrm{M}$ octopamine was applied, causing a typical increase in firing frequency. When the saline was then supplemented with 100 $\mu \mathrm{M}$ Rp-cAMPS and perfusion continued for 15 min, application of the same octopamine concentration produced a much smaller increase in firing frequency. A similar result was obtained in three recordings. RpcAMPS effect was not reversible; the normal response to octopamine did not return even after a prolonged washing period. Octopamine-induced PKA activation has previously been shown to occur in vivo in honeybee antennal lobe neurons (Hildebrandt and Müller, 1995) and in locust muscle (Walther and Zittlau, 1998). These results suggest that the octopamine receptors in spider trichobothria neurons are positively coupled with adenylate cyclase and act via a PKA-mediated pathway.

\section{Discussion \\ Anti-OAMB specificity and immunoreactivity}

The OAMB antibody was developed against a peptide sequence from an intracellular loop of a cloned Drosophila octopamine receptor (Han et al., 1998). In immunohistochemistry and in situ hybridization, it labeled Drosophila mushroom bodies (OAMB). Later it was shown that OAMB receptors are also present in Drosophila thoracicoabdominal ganglion, the female reproductive system, and mature eggs (Lee et al., 2003). OAMB receptors have high sequence similarity with cloned octopamine receptors from honeybee (Am $\left.\mathrm{oa}_{1}\right)$, cockroach $\left(\mathrm{Pa} \mathrm{oa}_{1}\right)$, and the sea slug $\left(\mathrm{Lym} \mathrm{oa}_{1}\right)$ (Grohmann et al., 2003; Bischof and Enan, 2004) and with the vertebrate $\alpha 1$ adrenergic receptors (Han et al., 1998). When Western blot analysis was performed from extracts of honeybee antennal lobes with the anti-OAMB antibody and an antibody against Am oa ${ }_{1}$, both identified bands at $78 \mathrm{kDa}$. In whole-brain extracts from both Drosophila and honeybee, four bands at 48,60,72, and $78 \mathrm{kDa}$ were found (Farooqui et al., 2004). We identified a band from spider brain extracts at $\sim 75 \mathrm{kDa}$ by Western blot, close to the calculated molecular weight of OAMB (Han et al., 1998).

To our knowledge, apart from Drosophila, anti-OAMB antibody or other antibodies against octopamine receptors have not been used in immunolabeling. Therefore, our findings of antiOAMB immunoreactivity in spider mechanosensory neurons are unique. Immunoreactivity (Fig. $2 A-D$ ) in spider leg hypodermis was very specific to mechanosensory neurons. Labeling was not found in the efferent neurons or glial cells that enwrap these neurons. Our results suggest that octopamine receptors are present on the spider leg mechanosensory neurons, concentrated in areas where action potentials propagate to axons. Action po- 
tentials in spider VS-3 neurons are initiated in dendrites (Gingl and French, 2003; Gingl et al., 2004), but an additional initiation site is probably located in the axon hillock, because these neurons can also fire action potentials when the dendrites are severed (Sekizawa et al., 1999). Interestingly, GABAergic inhibition also occurs in the axons (Gingl et al., 2004), indicating that this is an important modulation site. It is not known whether the octopamine-containing efferent neurons also contain GABA (Seyfarth et al., 1993) or how simultaneous release of both transmitters might affect the sensory neurons. Future research into this aspect is now required.

\section{Direct synaptic input to mechanosensory neurons}

Octopamine can act as a hormone released into the hemolymph or as a transmitter released from efferent endings close to the target cells (Roeder, 1999). In C. salei, octopamine-immunoreactive cells were found in the central ganglion complex (Seyfarth et al., 1993). Except for fine varicosities at the roots of peripheral nerves, octopamine-immunoreactive fibers were not seen leaving the CNS. HPLC measurements indicated that spider hemolymph contained free octopamine (Seyfarth et al., 1993), suggesting that octopamine may act as a hormone in peripheral targets. Our results indicate that octopaminergic efferent fibers directly innervate mechanosensory neurons.

Double-labeling with anti-OAMB and anti-synapsin (Fig. $2 D-F$ ) showed that, especially in the proximal parts of cell bodies, axon hillocks and initial axons, anti-OAMB-labeled clusters were close to the anti-synapsin-immunoreactive clusters in efferent fibers. Anti-synapsin immunoreactivity was more widespread than antiOAMB labeling, and many of the anti-synapsin-labeled presynaptic sites were probably attributable to nonoctopaminergic synapses. The strongest evidence for direct innervation of spider mechanosensory neurons by octopaminergic efferents came from the anti-octopamine immunolabeling (Fig. 6). Segments of fine antioctopamine-immunoreactive fibers were detected in the main leg nerve and above the axons of each sensory neuron, strongly suggesting that the octopamine receptors concentrated in this region are postsynaptic targets of octopaminergic efferents.

In locust metathoracic ganglia, anti-octopamine-immunoreactive DUM neurons were shown to form terminal networks on sympathetic nerves and longitudinal muscles. The latter were covered with octopamine-immunoreactive varicosities, but excessive background staining made it impossible to see whether similar varicosities were present above the sympathetic nerves (Bräunig et al., 1994). A similar problem with background staining may have hindered detection of anti-octopamine labeling in fine fibers of other preparations, in which antibodies that require glutaraldehyde fixation have been used. Here, we used an antioctopamine antibody on EDAC (see Materials and Methods)fixed tissue. The background staining in these preparations was minimal.

\section{Octopamine induced increase in sensitivity}

Trichobothria in the spider legs and pedipalps are air movement detectors used to localize flying insect prey. Different hairs are mechanically tuned to frequencies between 40 and $600 \mathrm{~Hz}$, and they adapt in a few seconds to single frequency stimuli (Barth and Höller, 1999). Here, we demonstrated that in $\sim 1$ min they also adapted to stimuli with a wide frequency range but continued firing at a plateau level for periods of at least 6 min (Fig. 4). Octopamine, and its precursor tyramine, increased the firing frequency, restoring it to approximately the preadaptation level. Similar increases in firing frequency in response to octopamine have been reported in other invertebrate preparations (Ramirez and Orchard, 1990; Ramirez et al., 1993; Matheson, 1997; Bräunig and Eder, 1998; Goaillard et al., 2004).

One hypothesis for modulation of mechanosensory neurons is that their frequency sensitivity could be changed by the modulator. This would allow neurons to be tuned to behaviorally more relevant stimulus frequencies as the situation changes. Our results indicate that this is not the case for octopaminergic modulation of trichobothria neurons. Octopamine changed the sensitivity of these neurons similarly at all recorded frequencies, with no effect on adaptation over this wide range of time scales (Fig. 6). However, octopamine did reduce the very slow adaptation occurring over a time scale of $\sim 1$ min (Fig. $4 B$ ), which would allow the receptor to maintain high sensitivity with repeated stimuli. Previous behavioral experiments showed that trichobothria are used to detect flying insect prey, which spiders can catch by a precise jump, even when blinded (Barth et al., 1995). Local release of octopamine may be used to allow specific sensory organs to maintain higher sensitivity than other organs with sensitivities that are not increased at this time or in this behavioral context.

\section{Phentolamine effects}

Phentolamine is an antagonist of $\alpha$-adrenergic receptors, and it also inhibits octopamine receptors (Roeder, 1999). Here, we demonstrated that phentolamine has an antagonistic effect on spider octopamine receptors (Fig. 7), but it also decreased the firing frequency of trichobothria neurons alone. Inhibitory effects of phentolamine were previously reported in locust and cockroach mechanosensory neurons (Ramirez and Pearson, 1990; Ramirez and French, 1990). This local anesthetic effect of phentolamine was believed to be caused by blockade of voltageactivated $\mathrm{Na}^{+}$channels. Inhibitory effects of phentolamine on $\mathrm{Na}^{+}$channels have also been described in vertebrate cardiac muscle cells, neurons and glial cells (Rosen et al., 1971; Northover, 1983; Reiser et al., 1983). In the spider, inhibition occurred at significantly lower phentolamine concentrations than in the cockroach or locust. This may be attributable to the range of stimulation frequencies that were used here, because the effect in locust and cockroach was achieved more easily when the neurons were stimulated with higher frequency (Ramirez and Pearson, 1990). We did not investigate further whether the inhibitory effect in the spider was truly dependent on $\mathrm{Na}^{+}$channels. Another hypothesis would be that there is a baseline stimulation of octopamine receptors that was blocked by phentolamine.

\section{Octopamine second-messenger system}

Our findings indicate that ligand binding to spider octopamine receptors activates adenylate cyclase and increases cAMP concentration, leading to the activation of PKA. However, this result does not exclude the possibility that other mechanisms may be activated. Octopamine has been shown to activate more than one signal transduction pathway by binding to one receptor. For example, in the cloned functionally expressed Lymnaea octopamine receptors, octopamine increased both cAMP and $\mathrm{IP}_{3}$ (Gerhardt et al., 1997a). Similar findings were presented from the cloned octopamine receptors of Drosophila and cockroach (Han et al., 1998; Bischof and Enan, 2004).

\section{Significance of local octopamine release}

Many arthropod sensory neurons are modulated by octopamine, but it has not been clear whether this modulation is achieved by 
an increased level of octopamine in the hemolymph or its local release from efferent endings. For example, locust forewing stretch receptor responded to octopamine levels that occur in hemolymph during stress (Ramirez and Orchard, 1990), suggesting that octopamine may have a role in increasing the responsiveness at the time of flight initiation. If octopamine were only released into hemolymph, it would affect all of the sensory neurons that have octopamine receptors, whereas local release from efferents would allow specific sensory organs to be modulated. This type of arrangement would make it possible to emphasize sensory input from specific sensilla relative to others. Depending on behavioral circumstances, both mechanisms, local and humoral release, are probably important.

\section{References}

Barth FG, Höller A (1999) Dynamics of arthropod filiform hairs. V. The response of spider trichobothria to natural stimuli. Philos Trans R Soc Lond B Biol Sci 354:183-192.

Barth FG, Humphrey JAC, Wastl U, Halbritter J, Brittinger W (1995) Dynamics of arthropod filiform hairs. III. Flow patterns related to air movement detection in a spider (Cupiennius salei Keys). Philos Trans R Soc Lond B Biol Sci 347:397-412.

Bendat JS, Piersol AG (1980) Engineering applications of correlation and spectral analysis. New York: Wiley.

Bischof LJ, Enan EE (2004) Cloning, expression and functional analysis of an octopamine receptor from Periplaneta americana. Insect Biochem Mol Biol 34:511-521.

Bohnenberger J (1981) Matched transfer characteristics of single units in a compound slit sense organ. J Comp Physiol 142:391-402.

Bräunig P, Eder M (1998) Locust dorsal unpaired median (DUM) neurones directly innervate and modulate hindleg proprioceptors. J Exp Biol 201:3333-3338.

Bräunig P, Stevenson PA, Evans PD (1994) A locust octopamineimmunoreactive dorsal unpaired median neurone forming terminal networks on sympathetic nerves. J Exp Biol 192:225-238.

Cooley JW, Tukey JW (1965) An algorithm for the machine calculation of complex Fourier series. Math Comput 19:297-301.

Degen J, Gewecke M, Roeder T (2000) Octopamine receptors in the honey bee and locust nervous system: pharmacological similarities between homologous receptors of distantly related species. Br J Pharmacol 130:587-594.

Evans PD (1981) Multiple receptor types for octopamine in the locust. J Physiol (Lond) 318:99-122.

Fabian-Fine R, Volknandt W, Seyfarth E-A (1999a) Peripheral synapses at identifiable mechanosensory neurons in the spider Cupiennius salei: synapsin-like immunoreactivity. Cell Tissue Res 295:13-19.

Fabian-Fine R, Höger U, Seyfarth E-A, Meinertzhagen IA (1999b) Peripheral synapses at identified mechanosensory neurons in spiders: threedimensional reconstruction and GABA immunoreactivity. J Neurosci 19:298-310.

Fabian-Fine R, Meinertzhagen IA, Seyfarth E-A (2000) Organization of efferent peripheral synapses at mechanosensory neurons in spiders. J Comp Neurol 420:195-210.

Fabian-Fine R, Seyfarth E-A, Meinertzhagen IA (2002) Peripheral synaptic contacts at mechanoreceptors in arachnids and crustaceans: morphological and immunocytochemical characteristics. Microsc Res Tech 58:283-298.

Farooqui T, Vaessin H, Smith BH (2004) Octopamine receptors in the honeybee (Apis mellifera) brain and their disruption by RNA-mediated interference. J Insect Physiol 50:701-713.

Foelix RF (1975) Occurrence of synapses in peripheral sensory nerves of arachnids. Nature 254:146-148.

French AS (1984) Dynamic properties of the action potential encoder in an insect mechanosensory neuron. Biophys J 46:285-290.

French AS, Holden AV, Stein RB (1972) The estimation of the frequency response function of a mechanoreceptor. Kybernetik 11:15-23.
French AS, Höger U, Sekizawa S-i, Torkkeli PH (2001) Frequency response functions and information capacities of paired spider mechanoreceptor neurons. Biol Cybern 85:293-300.

Gerhardt CC, Bakker RA, Piek GJ, Planta RJ, Vreugdenhil E, Leysen JE, van Heerikhuizen H (1997a) Molecular cloning and pharmacological characterization of a molluscan octopamine receptor. Mol Pharmacol 51:293-300.

Gerhardt CC, Lodder HC, Vincent M, Bakker RA, Planta RJ, Vreugdenhil E, Kits KS, van Heerikhuizen H (1997b) Cloning and expression of a complementary DNA encoding a molluscan octopamine receptor that couples to chloride channels in HEK293 cells. J Biol Chem 272: 6201-6207.

Gingl E, French AS (2003) Active signal conduction through the sensory dendrite of a spider mechanoreceptor neuron. J Neurosci 23: 6096-6101.

Gingl E, French AS, Panek I, Meisner S, Torkkeli PH (2004) Dendritic excitability and localization of GABA-mediated inhibition in spider mechanoreceptor neurons. Eur J Neurosci 20:59-65.

Goaillard JM, Schulz DJ, Kilman VL, Marder E (2004) Octopamine modulates the axons of modulatory projection neurons. J Neurosci 24: 7063-7073.

Grohmann L, Blenau W, Erber J, Ebert PR, Strunker T, Baumann A (2003) Molecular and functional characterization of an octopamine receptor from honeybee (Apis mellifera) brain. J Neurochem 86:725-735.

Han K-A, Millar NS, Davis RL (1998) A novel octopamine receptor with preferential expression in Drosophila mushroom bodies. J Neurosci $18: 3650-3658$.

Hildebrandt H, Müller U (1995) Octopamine mediates rapid stimulation of protein kinase $\mathrm{A}$ in the antennal lobe of honeybees. J Neurobiol 27:44-50.

Howell KMR, Evans PD (1998) The characterization of presynaptic octopamine receptors modulating octopamine release from an identified neurone in the locust. J Exp Biol 201:2053-2060.

Klagges BR, Heimbeck G, Godenschwege TA, Hofbauer A, Pflugfelder GO, Reifegerste R, Reisch D, Schaupp M, Buchner S, Buchner E (1996) Invertebrate synapsins: a single gene codes for several isoforms in Drosophila. J Neurosci 16:3154-3165.

Lee HG, Seong CS, Kim YC, Davis RL, Han K-A (2003) Octopamine receptor OAMB is required for ovulation in Drosophila melanogaster. Dev Biol 264:179-190.

Marmarelis PZ, Marmarelis VZ (1978) Analysis of physiological systems: the white-noise approach. New York: Plenum.

Matheson T (1997) Octopamine modulates the responses and presynaptic inhibition of proprioceptive sensory neurones in the locust Schistocerca gregaria. J Exp Biol 200:1317-1325.

Northover BJ (1983) A comparison of the electrophysiological actions of phentolamine with those of some other antiarhythmic drugs on tissues isolated from the rat heart. Br J Pharmacol 80:85-93.

Orchard I, Ramirez J-M, Lange AB (1993) A multifunctional role for octopamine in locust flight. Annu Rev Entomol 38:227-249.

Panek I, French AS, Seyfarth E-A, Sekizawa S-i, Torkkeli PH (2002) Peripheral GABAergic inhibition of spider mechanosensory afferents. Eur J Neurosci 16:96-104.

Panek I, Meisner S, Torkkeli PH (2003) The distribution and function of $\mathrm{GABA}_{\mathrm{B}}$ receptors in spider peripheral mechanosensilla. J Neurophysiol 90:2571-2580.

Pasztor VM, Bush BM (1987) Peripheral modulation of mechanosensitivity in primary afferent neurons. Nature 326:793-794.

Ramirez J-M, French AS (1990) Phentolamine selectively affects the fast sodium component of sensory adaptation in an insect mechanoreceptor. J Neurobiol 21:893-899.

Ramirez J-M, Orchard I (1990) Octopaminergic modulation of the forewing stretch receptor in the locust Locusta migratoria. J Exp Biol 149:255-279.

Ramirez J-M, Pearson KG (1990) Local anesthetic action of phentolamine on insect mechanoreceptors. J Comp Physiol [A] 167:475-483.

Ramirez J-M, Büschges A, Kittman R (1993) Octopaminergic modulation of the femoral chordotonal organ in the stick insect. J Comp Physiol [A] 173:209-219. 
Reiser G, Löffler F, Hamprecht B (1983) Tetrodotoxin-sensitive ion channels characterized in glial and neuronal cells from rat. Brain Res 261:335-340.

Roeder T (1999) Octopamine in invertebrates. Prog Neurobiol 59:533-561.

Roeder T, Seifert M, Kahler C, Gewecke M (2003) Tyramine and octopamine: antagonistic modulators of behavior and metabolism. Arch Insect Biochem Physiol 54:1-13.

Rosen MR, Gelband H, Hoffman BF (1971) Effects of phentolamine on electrophysiologic properties of isolated canine Purkinje fibers. J Pharmacol Exp Ther 179:586-593.

Sekizawa S-i, French AS, Höger U, Torkkeli PH (1999) Voltage-activated potassium outward currents in two types of spider mechanoreceptor neurons. J Neurophysiol 81:2937-2944.
Seyfarth E-A, Hammer K, Spörhase-Eichmann U, Hörner M, Vullings HG (1993) Octopamine immunoreactive neurons in the fused central nervous system of spiders. Brain Res 611:197-206.

Shannon CE, Weaver W (1949) The mathematical theory of communication. Chicago: University of Illinois.

Thorson J, Biederman-Thorson M (1974) Distributed relaxation processes in sensory adaptation. Science 183:161-172.

Van Poyer W, Torfs H, Poels J, Swinnen E, De Loof A, Akerman K, Vanden Broeck J (2001) Phentolamine-dependent adenylyl cyclase activation in Drosophila Schneider 2 cells. Insect Biochem Mol Biol 31:333-338.

Walther C, Zittlau KE (1998) Resting membrane properties of locust muscle and their modulation II. Actions of the biogenic amine octopamine. J Neurophysiol 80:785-797. 